Portland State University

PDXScholar

Where We Are Going Next, Together

Archive Organized by Project Title

$1-2-2020$

\title{
Where We Are Going Next, Together
}

Jeff Kasper

Micaela Martegani

Follow this and additional works at: https://pdxscholar.library.pdx.edu/wwgn_t

Let us know how access to this document benefits you.

Recommended Citation

Kasper, Jeff and Martegani, Micaela, "Where We Are Going Next, Together" (2020). Where We Are Going Next, Together. 1.

https://pdxscholar.library.pdx.edu/wwgn_t/1

This Book is brought to you for free and open access. It has been accepted for inclusion in Where We Are Going Next, Together by an authorized administrator of PDXScholar. Please contact us if we can make this document more accessible: pdxscholar@pdx.edu. 


\section{Where We Are Going Next,} Together

\author{
Micaela Martegani \\ and Jeff Kasper
}

For fifteen years, More Art has fostered the power of art to bring neighbors together, first in our Chelsea home, then New York City-wide, and now across municipal and even national borders. During that time, we have shaped opportunities for more than fifty mid-career and established artists to realize largescale, socially engaged public art commissions, and have equipped an equal number of emerging artists and community leaders with the tools and resources to do so tomorrow. As we approach the third decade of the twenty-first century, the field of socially engaged art and social practice is expanding, becoming more popular, and dare we say, fashionable. More and more organizations, small and large, are beginning to embrace the elements that are uniquely central and specific to More Art's work: community involvement, site-specificity, accessibility, interdisciplinary partnership, and public collaboration. For the next fifteen years and beyond, we will continue to delve deeper and push further, expanding the field achievable by socially engaged public art.

As we build towards the future, we continue to ask ourselves: what types of support do artists need to create impactful work? We favor depth of engagement as a metric in determining how we contribute to social change. Whiversities, and museums focus on the organizations, universites, and museums focus on the important work of teaching emerging social practitioners and youth, forteng the placenaking of and cultural policy, offering philanthropic support and providing documentary storytelling and short-term and providing documentary storytelling and short-term organizations that works directly with artists and the public to directly incubate a large breadth of visionary works of art. More Art-supported projects take on a range of forms, including those rooted in place or geographically bound borders, and others that experiment with new approaches to public interaction writ large. Many live on beyond our initial support, morphing into lifelong practices, campaigns, models, and reenacted durational works. But our key motivation persists: to provide strategic support to ambitious, socially engaged art that may not happen otherwise. We believe the opportunity to achieve the scale, scope, and success that is possible when artists and cultural producers work collectively and flexibly in teams and in boundary-crossing partnerships with experts outside the arts is all too rare. That is the style of art support we practice;
that is the level of support we envision for the field at large.

A significant portion of the last fifteen years has been spent articulating the way we work. We are privileged to have had the opportunity to craft this book as a point of and ever-changing identity together through many diverse projects with hundreds of people, in wildly different protexts, as the chapters in this book illustrate, and to contexts, as the chapters in this book illustrate, and to like a set of principles and processes that guide our work Think of it as a manifesto if you will, a blueprint if you must, but definitely consider how it applies to your own work as a public steward, ally, student, social practitioner, or active citizen. We hope it will inspire you to take up the charge in co-creating works of art with people in the communities you are a part of, to shape the world you want to live in tomorrow. 
What distinguishes our methodology is our long-term commitment to artists, community partners, and

considerable projects. There are two areas in particular that we find to be crucial in doing this type of work: partnership building and articulating an ethics of public engagement.

Partnership Building

Socially engaged art should catalyze the power of valuealigned social justice organizations, groups, and individuals, and when applicable, add to the reach of grassroots and popular movements by drawing on the power of public art. Partnerships must be synergetic and reciprocally beneficia to all involved.

Ethics of Public Engagement

Stewards of public engagement should employ humility as a deep listening device, honoring the insight of the communities and individuals they identify and work with Public art projects are living organisms, which will only thrive when all parts are accounted for and healthy. A healthy and equitable project is a project in which the artist, site) arl fully, issues (or content), and the place (or broad and abstract or intangible shoulds, but prioritize the real experiences of people, underscoring the very hum dimension of making and

What comes next are our suggestions for the development of socially engaged public art projects. We believe interdisciplinary arts organizations should invest significant resources, time, and organizational capacity, at every phase of project building, over long periods of development, to work in a community in deep, thoughtful ways. We don't encourage that projects engage in timeframes of less than two to three years. Sometimes our work takes nearly four years of finetuning before being presented to the general public. This is in obvious tension with the all-too-common three-month to one-year standar of commissioning opportunities, residencies, and grant support found in the American visual arts landscape today. of course, a commissioning organization cannot work on a project forever; that is never our intent or goal. But we do project forever, that is never our intentor goal. But we do belime to support during those early stages.

This is a call to action to supporters and creators of this kind of work, a plea to slow down and focus on the details when aiming for meaningful collaborative impact, to hold the value of crafting cultures of cooperation as a goal in and of itself.

We propose the following sequence of planning and production:

+ Project Incubation and Research

(including the use of archival materials, literature on the subject, interviews, site-based studies, and so on.)

+ Action-based research, or gaining insights through education, community exchange, and public engagement

+ Co-production of public art led by artists and publics

+ Contextualization through public programs

+ Circulation of art and ideas through multiform media and documentation

+ Evaluation through applicable data collection and analysis 
During the early phase of project incubation and research, artists and non-arts stakeholders learn by embedding topic affecting puin the discourses and sites of any given form afecting public life, while experimenting with and formulating strategies around how art is best suited to

Action-based research takes place in spaces of learning, be they schools, laboratories, studios, or the street. A given social topic or situation (for example, the negative perception of United States) is investigated by participants thrudes in the artistic experimentation in various media. be considered cultural producers and artists in their os should and thus should be met in the frontlines of issue ecologies complex interconnected factors that make up a sociag or situation-and brought to the table to shape the project.

People from all backgrounds should be encouraged to see themselves as producers of culture through the co-production of public art, by collaborating with self-identified artists to synthesize information through participatory artmaking. Artists take a leadership position in this process, and More Art operates as curator, facilitator, strategist, and/or producer, working as a connector between all project stakeholders. The process of coproduction should involve staging a "final" work exp as an art artifact, obect, pefformance, learning tool, or informative engage in the conversation.
ens who need it most in order to

We strive to demystify art and the process of collective artmaking through contextualization, by developing supporting public programs. Together with the artists, stakeholders, the project and determin what example, we might bring lawyers and policymaration (for conversation with artists, to speak about different perspectives on contemporary immigration).

During the phase of circulation and documentation, we ask: what is the best way for people to learn about the artwork when they were not involved in its creation or initial presentation? We document each project through photography and video, use storytelling on social media and the Internet. and work with outside journalists and press outlets in ord to reach a larger public consciousness and a larger audience. Creating projects of a social or community engaged nature always requires producers, artists, partners, and audiences to articulate information about and provide evaluation of what makes the work successful or impactful. Impact must be based on the objectives the project sets out to accomplish and how art relates to that imperative. A organizing, for example, may have a quantitative goal, otherwise known as "exposure"; whereas a project that seeks to get a specific group to express their perspective on an issue may be deemed a success when a smaller, targeted number of individuals are able to contribute their ideas on a public stage, otherwise known as "depth." We find quantification to be important only in certain cases (even though it is the de facto form of evaluation by philanthropic funders and corporate investors), while the qualitative approach generally leads to a deeper understanding of how we matters to the people who create and experience testimats dat in social practice ages, evews, and surveys. As the field of of concern.

What holds this all together is what we call a theory of change. This is where we find clarity in what we do and why we do it. You can think of it as our politics, or how we thin progressive, inclusive change can happen, and where we defines long-term ecology of change. A theory of change necessary preconditions. It is a starting place to understand the relationship between the social problem an art experience addresses, the change it seeks to prom 
This is our theory of change:

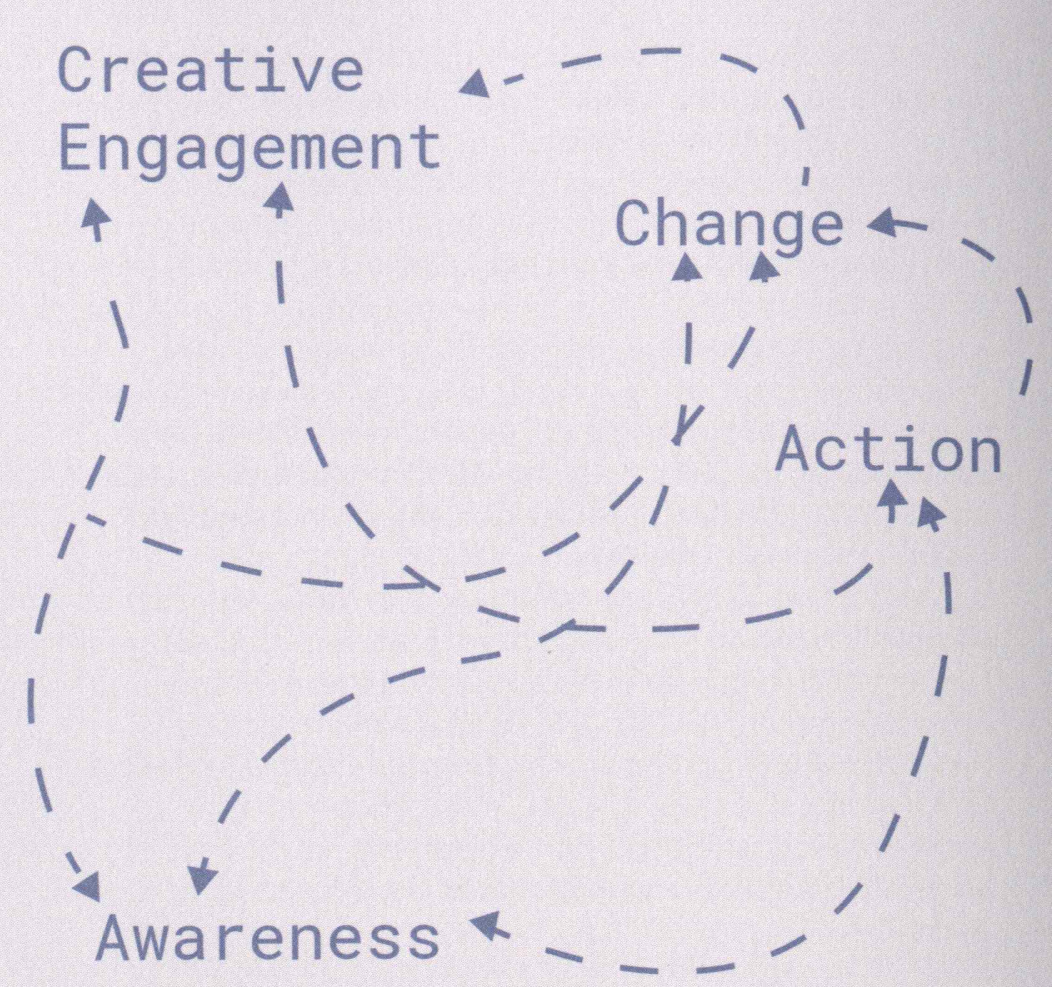

In our work awareness of a social issue should only ever be an initial goal. What we recognize as the role of public art in progressive change is what we call Creative Engagement, which gets people to feel, not just think about, the topics that affect their lives (and their neighbors' lives) This can include actionable

storytelling and consciousness building through interdisciplinary partnerships and multi-sensory, participatory art experiences in public spaces. Ultimately we are interested in modeling how to get involved by actually doing so creatively. crafting YOUR Theory of Change

A theory of change often uses a diagram or chart to describe a A theory of che should not be considered as being strictly visual.

The best theories of change demonstrate rationale and include:

An introduction to what the theory of change is and a description of the process you have been through to create it including who has been involved.

An analysis of the context and situation, discussing the background to the project and outlining the problem in society you are trying to address, your problem in society you are trying characteristics. this is sometimes called a "situation analysis."

A "narrative theory of change": a written narrative A "narration, to theory-of-change diagrams. This is explored in more depth later in this guidance.

+ References to existing evidence that relates to your stated theory of change, including evidence that you organization has already collected and any relevant published research

+ Plans for measurement and evaluation that arise from the theory of change including the details of the the theory of che collect to test whether the theory data "measurement framework." 
According to Americans for the Arts, a theory of change can help arts and social change organizations to

+ focus on conditions or context that can

sharpen the articulation of outcomes

+ narrow and specify outcomes and strategies, avoiding those that seem too broad or are difficult to define or quantify

+ see what is possible (and not possible) to achieve with your arts-based program or project

+ think about what inputs might be needed-yours and others-and when/where your input(s) might be most catalytic or strategic

+ examine whether or not your intervention will have a meaningful or powerful effect

+ avoid straying off course when unexpected events or inputs emerge

+ practice evaluative thinking

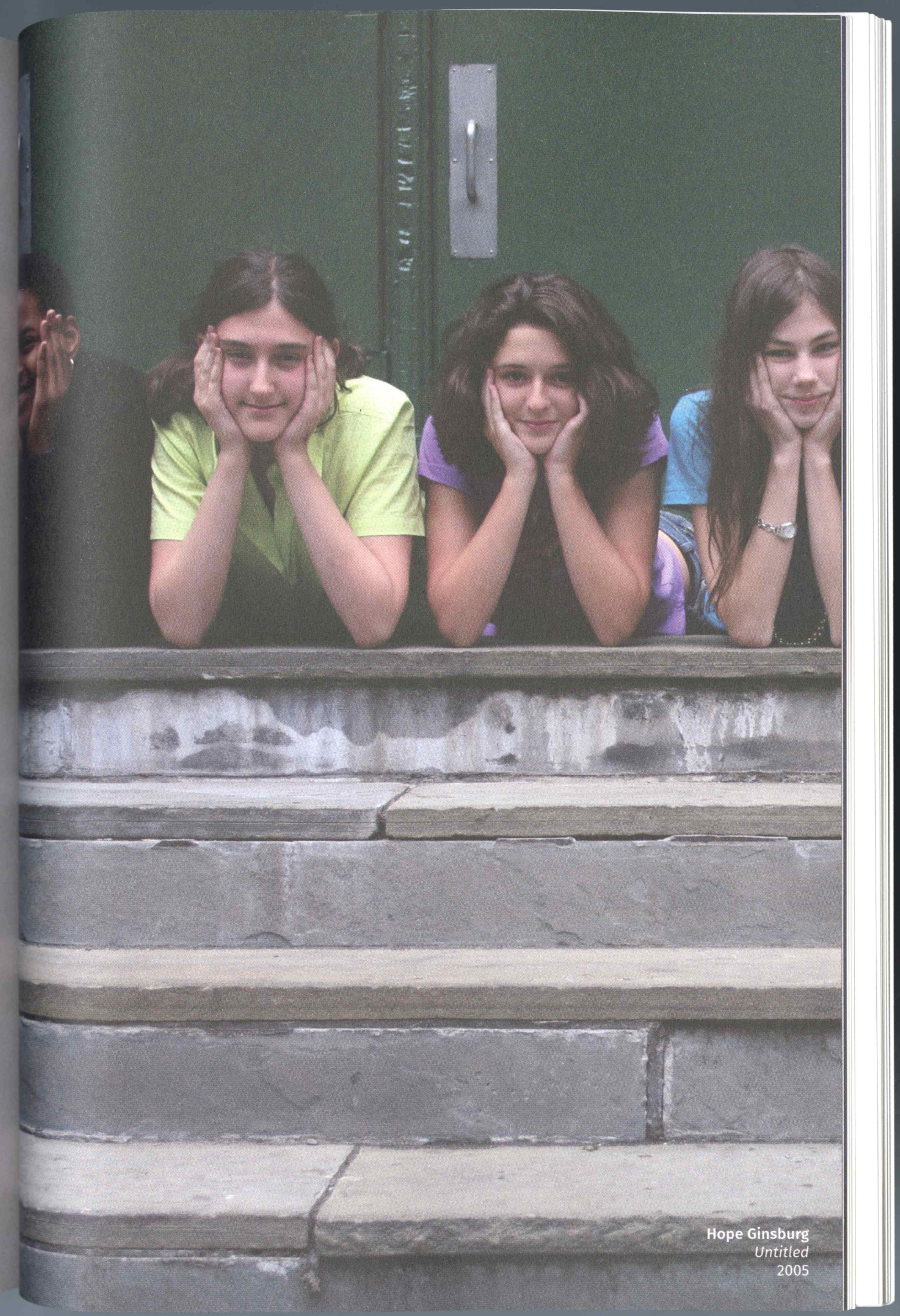


What does the future of socially engaged art look like?

Thest that 2040 the impacts of human and we will be facing the climate change wil-human and post-Anthropocene era. It is prospect of a post-ists in the future will have to confront the inevitable that anter divisiveness and competition wrought by potential for gesource insecurity. Our conception of migration Al as well as ally altered as environmental realities such as may be zadicallo force us to redefine our understanding of tooding horders. Movements around social equity and human rights will have to continue to grow and join forces as citizens assert their demands for political and cultural representation. Art will evolve as well, becoming increasingly din form and in content, like we have expected.

exact role that art will play, but pedict the exact role that art wil play but based on our frontline involvement educated guesses.

- Art will take an active role in Art will take an active role in shaping society and will be consider critical to politics, ratherthan autonomous or just a reflection the time. It will define the times.

Art will transform ways of living in the age of climate disaster and the end of the Anthropocene.
+ Art will model equity and radical inclusivity.

+ Art will lead new expansion of participatory and direct democracy practices

Socially engaged art is the testing ground for building Socially engaged art is the testing of collectivism yet to possible futures, models rore.

We spent our first fifteen years as an organization defining We spent our for the critical the way art-in particular public and socially engaged artplays in society, and of the ever-more relevant role that it will plays in sochave in the next twenty years, as we grapple with earth-shattering issues. Even if the terms "socially engaged art" or "social practice" become obsolete and are replaced by new ones in a continued transformation of the field, the idea of art being more collaborative and inclusive, inextricably linked to equity, social justice, and direct democracy practices, will gain more and more traction and urgency. In an increasingly fragmented and disconnected world, we predict that people will fight for authenticity, connectedness, and a sense of belonging, individual, as well as speak to a shared future. Arist Alfredo Jaar has written that, "Regardless of what others believe, the center of the world is everywhere where we can speaking to the universal and the $p$ an art. We believe we need to recenter art towards a moden of person ultimately acts on the world at large, and vice versa.

We have been struck by the foresight of the assessment that iter and acivis Wendell Berry made in 1981 about European writer and activis with vision but not sight. We see this as one settles con a ngerous pitfalls in our society, particularly when it comes to thinking of doing good. Art celebrates diversity with all its idiosyncrasies. As social practice producers, we may become so certain of our positive role that we manufacture expectations regarding how we should best represent the concerns of a community. As well-intentioned as we might be, there is the risk of imposing our own vision of the perfect resolution without paying attention to, or seeing, the actual 
realities of a community and truly listening to the individuals involved. Some projects are meant to reach thousands of peple, sothers only one person; we assert the value, success, and impact of each and all those in between. Informed by this awareness, this listening and learning with humility, in thoughtful collaboration with local organizations working on the ground, and the acceptance of criticism and our own shortcomings along the way, socially engaged public art is ideally positioned to act in the next twenty years as a catalyst for experiential, long-lasting change.

\section{$\Leftrightarrow \cos$}

$\bullet$

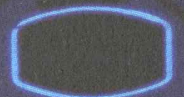

See Tom Finkelpearl, introduction to What
We Made: Conversations on Art and SScoili Cooperation
(Durham, North Carolina: Duke University Press, 2012), Just a note: our theory of change is always up for improvement, and yours shoutd be, too. We
also want to acknowledge that we are representing this theory linearly, but it's far more rhizomatic than

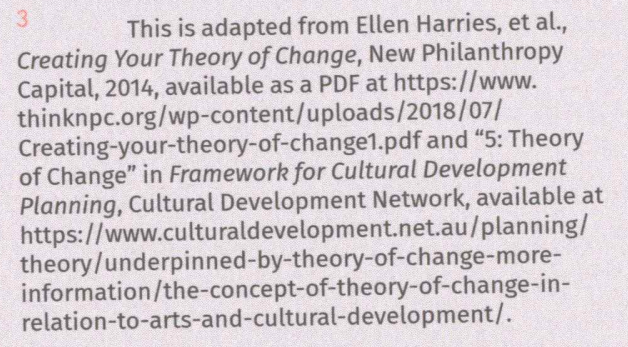

October, 2018. The Anthropocene ist reepoch the . Including climate change. See Elizabeth Kolbert, The
Sixth Extinction: An Unnatural Storyy (Henry Holt and Company, 2014.

In a statement to the authors, regarding trip to finland, Jaar waited for a boat to take him on the four-hour journeys near-emptty boat was leaving at 5 :45 $\mathrm{a}$ a.m.; the captain told him that a boy living on a small island along
route had to get to school on the main island. Dear Markus consisted of a series of billboards with etters from Finnish authors placed across the islands on the
route to Utö from Pärnäs in Finland, made specifically Based on "Articulate a theory of
change" from the Arrs \& C Civic Engagement Too Kit, Animating Democracy and Americans for
the Arts, 2008. This tool provides an example and a simple exercise for creating a logic
model. See: https://animatingdemocracy.org/

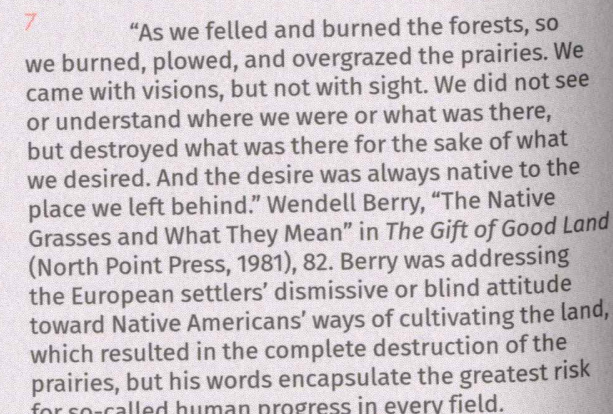

